\title{
Productive Play: Beyond Binaries
}

\author{
Bonnie Nardi', Celia Pearce ${ }^{2} \&$ Jason Ellis ${ }^{3}$ \\ 'Department of Informatics, University of California, Irvine, CA, USA, ${ }^{2}$ Georgia Institute of Technology, \\ Atlanta, GA, USA, ${ }^{3}$ IBM TJ Watson Research Center, Hawthorne, NY, USA
}

\section{ABSTRACT \\ In this article we review and analyze rotions of productive play, reporting the results of a workshop held at the University of California, Irvine in May 2008.}

Keywords: play, work, virtual worlds

This issue of Artifact expands on the notion of "productive play" (Pearce, 2006a) to describe play activities that begin to transition into creative, organizational, or "work-like" activities (Castronova, 2001; Yee, 2006), but here are broadened to include a range of cultural practices in which work and play converge in online play environments. Special Issue Editors Ellis, Nardi, and Pearce convened a workshop in May 2008 that comprised experts in fields ranging from computer-supported collaborative work, to the anthropology of virtual worlds and massively multiplayer online games (MMOGs), to the design of 2D, 3D, and text-based social environments to explore these issues from a range of angles. Sponsored by the National Science Foundation, this fruitful discussion yielded a number of insights, some of which will be examined in this paper. One of the most notable of these was the need to move away from a binary language with which to think about work and play, and find new ways to talk about their convergence. The canonical works of play theory, such as Huizinga's Homo Ludens (1940), Caillois's Man, Play and Games (1961), and Sutton-Smith's The Ambiguity of Play (1997) specifically define play as "not work", or the "opposite of work", even while they assert its importance in constructing and framing culture. Yet are these activities really as diametrically opposed as these definitions imply? Is there better terminology that can evoke a more nuanced picture of cultural practice? Do words like "effort" and "creativity" offer us alternative ways to explore the spectrum of activities that fall within this rubric? This paper will engage questions that arose out of the workshop discussions, more often left unanswered than not, and set the stage for a rethinking of traditional binaries around work and play.

\section{PRODUCTIVE PLAY?}

Half of us don't realize what was behind all of it. Hard, grunt work. The determination to learn this encounter to its fullest extent. The next day after 3 hours of tries on Illidan, he finally fell, and his cruel grasp on the world of Outland had been released by Nihilum. (Website posting by Nihilum guild on their world-first defeat of Illidan in World of Warcraft)

At first glance, the term "productive play" may appear to be an oxymoron, or at the very least, a blending of incompatible practices. Canonical works in game studies, especially those that pre-date digital games, such as those of Huizinga (1950)), Caillois (1961), and Sutton-Smith (1997), define play and games as being inherently unproductive, although Sutton-Smith also argues that play should be valued for its own sake and not for the "work" it does. One could even argue that play is not only not work but the very antithesis of work in every way. Yet emerging trends indicate that activities associated with the cultural practices we generally recognize as "work" and "play" are increasingly converging. For example, much attention has been paid in the popular press to the emerging class of professional video game players. And the exchange of virtual money for real-world currencies has given rise to a number of practices, from virtual worlds participants who have parlayed virtual businesses into real-world cash and even income (MacMillan, 2007), to "gold farmers" hired to collect virtual currencies and items from games such as World of Warcraft to be sold to players who wish to avoid the "grind" of leveling characters and generating game gold (Dibbell, 2007). On the other hand, industry, academe, and the military have begun studying and leveraging networked play spaces to support distance collaboration, team-building, training, marketing, and retail, and other activities traditionally associated with work and productivity. The term "productive play" was originally coined to describe the former kinds of activities, reporting forms of fan cultures in which players in online games and virtual worlds began exhibiting behaviors that were more and more work-like, particularly in the realm of community organization and content creation (Pearce, 2006a). For the purposes of this discussion, we have extended the term to include the latter form of productive play, in which play space is co-opted and appropriated for real-world work-related applications. 


\section{THE HISTORY OF THE FUTURE}

One of the key problems identified by the workshop organizers was the tendency towards historical amnesia within IT fields, but particularly within the domain of games and virtual worlds. Claims of "firsts" abound, though few are valid. To mitigate this problem and create a solid foundation for our discussion, we invited bona fide pioneers who had been behind a number of significant "firsts." Chip Morningstar and Randy Farmer kicked off the discussion with a presentation of Lucasfilm's Habitat, their 1986 online graphical chat space (Farmer \& Morningstar, 1991). Habitat was the first online environment to use "avatars" (graphical representations of players), a term which Morningstar and Farmer adopted, and which introduces our first theme, identity. Running on dial-up modems through the early online service Quantum Computer Services, with low-resolution graphics and a highly constrained color palette, they were able to create an environment that gave rise to one of the earliest online play communities, through several iterations, audiences, and corporate overlords. Emergence was a common outcome: the two pioneers pointed out that players will take whatever affordances are offered to them and appropriate them creatively to their own ends. At the same time, they warned of the "tyranny of emergence": while we all aspire to letting cultures form themselves in a bottom-up fashion, we can never forget the "hand of God" on high which rules over everything. In the context of these environments, we thus must ask ourselves, who is the designer and what are the limits of leaving things to shape themselves?

\section{Pushing these limits was at the heart of} LambdaMOO, the first user-created world, an object-oriented MUD created by Pavel Curtis (also in attendance at our workshop) in 1990 at XeroxPARC (Curtis, 1992). An experiment that began as a text-based simulation of the designer's home, LambdaMOO laid the foundation for contemporary worlds such as Second Life, as well as arguably being among the first instantiations of what would later come to be known as "Web 2.0". LambdaM00 was different from Habitat not only in that it was strictly textual and entirely user-created, but also in that it aimed to represent contiguous space. This introduces our second theme, space, particularly the question of space-as-metaphor. Most virtual environments today are organized around some central idea of spatiality, even though in practice spatial metaphors are often bypassed in favor of more "efficient" means of travel, such as teleporting. Habitat was not beholden to adjacencies or spatial contiguousness, and while LambdaMOO (which is still operating) is contiguous; its textbased representation allows for tremendous elasticity in matters such as scale and feasibility. Environments are more poetic and thus less subject to the constraints of constructs such as "gravity". Today's virtual worlds and MMOGs are surprisingly conventional in that, by and large, they operate within a premise of contiguous, feasible space (Klastrup, 2003; Pearce, 2008). Where spatial metaphors are strictly upheld, it may take hours to traverse a world. In user-created environments, players who wish to transcend conventional space must take considerable liberties with the spatial constraints presented by designers in order to bend the world's rules to their will.

LambdaM00 was eventually transformed into Jupiter, a professional environment for distributed work in which all in-world content was editable by users. In Jupiter, the virtual world was augmented by cameras in the real-world workspace, which were used to create a sense of ambient copresence. For example, even if one is not actively communicating with another user of the system in real time, one can still use the video feed as a window into their office, passively observing them and assessing their interruptibility. This affordance of the system created opportunities for serendipitous interaction that did not exist before - using video to get another user's attention or find appropriate times to physically enter his or her office to ask a question. While some of the more radical aspects of LambdaMOO ended up falling by the wayside in this application, a number of interesting patterns emerged that we can see in more contemporary practices, such as Nardi's observation that co-workers connected via online communication will sometimes connect for the sake of keeping in touch, even if they do not have a pragmatic agenda for doing so (Nardi, 2005).

From here we moved to the mid-1990s virtual worlds boom. Bruce Damer (this issue) describes his founding of the Avatars! Conference (originally Earth to Avatars) in 1996, which eventually became the first such event to be held in a virtual world. This generation of virtual worlds was highly influenced by science fiction, in particular William Gibson's Neuromancer (1984), in which the term "cyberspace" was originally coined, and Neil Stephenson's Snow Crash (1997), which introduced the term "metaverse" and popularized the term "avatar", arrived at independently of Morningstar and Farmer. The technical constraints of the early Internet produced in some ways a much more experimental environment, with a variety of challenges: limited bandwidth and graphical capability, for example, meant low-polygon avatars. In response to this challenge, avatars and environments tended to be more stylized than today's. In addition, humanoid avatars were not as common as they are today, although we see a growing use (mostly through emergent practices of players) of more experimental and abstract avatar representation. (Players appear at conferences in Second Life as everything from a fairy to a "Furry" (anthropomorphized cartoon animal) to a Jell-0 mold.) Virtual worlds of this period included 2D chatrooms of The Palace, to the heads-only lip-synched social space of OnLive! (now DigitalSpace Traveler), to Active World's LambdaM0O-like player-created environment. 
Today, corporations such as IBM, Intel, Sun, Microsoft, Xerox, and many others are experimenting with virtual worlds for work. These explorations are motivated by the high cost of travel and the need for co-presence and team-building among distributed co-workers. IBM, for example, has 400,000 employees across the globe. How can geographically scattered teams and ad hoc groups within the organization collaborate productively? Since 2006, a grassroots group within IBM known as VUC, or Virtual Universe Community, has spearheaded efforts to promote virtual worlds for IBM employees. Co-editor Ellis has been working with this group, which provides collaboration and communication infrastructure for virtual worlds research as well championing discussions about the ways in which virtual worlds can be shaped to meet IBM's corporate needs. The VirtualworldSIG interest group (http://virtualworldsig.com/) in Silicon Valley promotes awareness of virtual worlds research, technology, and use for organizations. Its bimonthly meetings (taking place in physical and virtual settings) provide an opportunity to connect people with common interests through presentations, workshops, and panels.

Despite Habitat having made its appearance in the mid-1980s, virtual worlds platforms for organizational use are still in flux. The technology is neither robust nor mature. Rohall et al. (2008) noted that, "Existing multi-user virtual worlds built with commercial game engines or on top of systems like Second Life all suffer from the same problems: heavy requirements on CPUs, disks, video cards, and networks. They just don't work well on corporate computers and networks where people must use other applications such as email, word processors, and web browsers." Not only are the virtual worlds applications sluggish (and subject to crashing), they make switching to other necessary applications slow and cumbersome.

Yankelovich and Kaplan (2008) experimented with Second Life, Forterra's Olive, and Sun's Project Wonderland to study the effectiveness of giving presentations in a virtual space. They noted that, "[B]eing in the same virtual space with others interested in a common topic was compelling. Interacting informally with people before and after the presentation is something that no other distributed meeting technology enables." However, serious problems marred the presentations.

Positioning the audience and the presenter was difficult, a lack of precision pointing interfered with the presenter's ability to focus on a particular aspect of a slide, and, most crucially, the systems' audio was inadequate. The authors observed, “Unfortunately, audio is one of the most problematic aspects of virtual world communication". Problems with volume, clarity, and echo impaired the presentations.

Technical limitations appear to be a significant barrier in the way of virtual worlds becoming as ubiquitous in work environments as phone conferences or email. Some developers be lieve that one solution is to reduce such worlds to only their most essential features. Others support continued technical development to sustain the promise of immersive 3D virtual reality (or something close). Rohall et al. (2008), for example, are moving their development efforts at IBM toward lightweight systems that support avatars but not necessarily a three-dimensional geography. They believe that what is most essential about virtual worlds is the people element, i.e. support for social interaction. They plan to abandon game engine client technology in favor of Flash-based web technology, which they believe is friendlier given today's computing resources. Yankelovich and Kaplan (2008), on the other hand, hold out the promise of future virtual worlds that will be capable of rendering 3D space effectively, for example to enhance presentations with virtual tours "at multiple sites, far-flung cities, or even several galaxies". (Such differences may in part reflect the authors' reflective business orientations; a great deal of IBM's revenue comes from services, while Sun manufactures powerful computers.) Like Sun, Linden Lab is betting on the continued importance of the rendering of $3 \mathrm{D}$ space. Second Life is being reshaped to meet corporate needs such as security, privacy, intellectual property, back-up, reliability, and tuning to available computing resources (Kamalsky, D., personal communication, November 2008). Some efforts go so far as to attempt to faithfully reproduce the real world in fine-grained detail. For example, Syamsuddin and Mayangsari (2008) maintain parallel universes: a robotic space of action with a virtual representation of the space.

In addition to technical barriers, users of environments like Second Life face numerous other challenges to adoption. Based on their research deploying virtual worlds inside a large corporation, Bessiere et al. (2008) detailed five central issues impeding adoption of virtual environments in business: initial motivation, technical difficulties, interacting competently, becoming socially proficient, and finding compelling activities. This work exposes issues that go beyond processor power and operating system to motivational, social, and content relevance concerns. Ultimately, all of these challenges must be addressed in concert for adoption of virtual worlds to succeed on a broad scale.

These issues are not merely an inconvenient roadblock on the way to virtual bliss. They expose fundamental questions about why organizations are attempting to adopt technologies largely associated with gaming and leisure for serious corporate objectives. In part what motivates enthusiasm for virtual environments is the observation that people happily spend hours in and around the worlds on play activities that look increasingly work-like. Whether such activities are work or play (which may be entirely subjective and thus evade simple categorization; see Nardi, 2008), certain activities, on their surface are, undeniably, work-like. 
One example is the emergence of knowledge bases and guides, such as forums, FAOs, blogs, wikis, surveys, inventories, and other documents that players create and make available for free on the Internet. For instance, player-created El's Extreme Anglin' - World of Warcraft Fishing Guide (http:// www.elsanglin.com/), which provides tips on fishing and preparing magical foods using fish, is more beautifully organized, written, and laid out than many high-end business publications. This site was created by a player who enjoys World of Warcraft fishing. Their motivations were posted to an official Blizzard Forum in 2006:

Fishing is a remarkably popular activity. Unfortunately it is not well documented. I searched long and hard for a complete copy of Nat Pagle's Guide to Extreme Anglin', but I could not find one. So I decided to write my own book: El's Extreme Anglin'. Available now from all good Gnomish fishing suppliers. (http://forums.wow-europe.com/ thread. html?topicld=15882083\&sid=1)

Today the Fishing Guide is sustained by advertising, which further blurs the lines between work and play. This parallels the trajectory of a number of shared game knowledge bases, such as Thotbott, which eventually become commercialized. A simple web search will turn up thousands more World of Warcraft related links containing player-generated content.

Corporations have noticed the care with which player-generated materials are crafted, and the markets that arise around such goods. Some hope is to import the playful enthusiasm for work-like tasks, such as documentation and knowledge sharing, into the workplace. Others are more interested in the potential of virtual worlds to help users develop leadership skills (IBM, 2007; Reeves \& Malone, 2007). It is a vexing theoretical question as to whether it is play itself that inspires outpourings of player-generated content, or whether the space and freedom to create - conditions that could be replicated in the workplace - are generative of such content.

It is clear that players themselves use work-related terms to describe their activity. One player in Nardi's World of Warcraft guild wrote on the guild website:

I am stuck back at work, and it's blessidly [sic] quiet enough for me to do some research on becoming a better [player]....

This player dismissed her "work", saying she was "stuck" there, but undertook a work-like activity - research - to become a better player. She went on to describe the (player-generated) websites she was consulting and the topics she was researching, which included very fine-grained game minutiae.

Some players create software to extend World of Warcraft. They write, debug, distribute, and update software "addons", or "modifications" which change the user interface. While modders write for free, some enterprising players bundle up the thousands of available mods, test for viruses and so on, then make the mods available for free download at distribution sites such as curse.com. Such sites have paid employees, and generate advertising revenue. Here we see how work and play mix, or, more precisely, how they may flow into one another.

Another work-like play activity is theorycraft the process of mathematically analyzing game mechanics in order to gain a better understanding of the inner workings of the game. Such discoveries are made by designing and running careful experiments, usually with many interacting variables. Players publish the results of the experiments on websites such as elitistjerks. com. They form temporary teams to collect more data than a single player could. They discuss the meaning of the experimental results and use them to tune their play performance. We are not aware of any revenue associated with theorycraft, but theorycrafting activity seems very much like some of what engineers might do at work.

John Dewey said, “No one has ever watched a child intent in his play without being made aware of the complete merging of playfulness with seriousness" (2005). So perhaps it is not surprising that work and play share common ground, that players voluntarily establish work-like activities, such as writing documentation, or testing game mechanics, as part of play. Indeed it is perhaps the very quality of seriousness that in part colors play as a compelling activity.

\section{THE FRAMES OF "PLAY" VS. "WORK"}

Tom Sawyer's rival, Ben Rogers, approaches, mocking Tom.

“Say - I'm going in a-swimming, I am. Don't you wish you could? But of course you'd druther work - wouldn't you? Course you would!"

Tom contemplated the boy a bit, and said:

"What do you call work?"

"Why, ain't that work?"

Tom resumed his whitewashing, and answered carelessly:

"Well, maybe it is, and maybe it ain't. All I know, is, it suits Tom Sawyer."

"Oh come, now, you don't mean to let on that you like it?"

The brush continued to move.

“Like it? Well, I don't see why I oughtn't to like it. Does a boy get a chance to whitewash a fence every day?"

That put the thing in a new light. Ben stopped nibbling his apple. Tom swept his brush daintily 
back and forth - stepped back to note the effect added a touch here and there - criticized the effect again - Ben watching every move and getting more and more interested, more and more absorbed. Presently he said:

"Say, Tom, let me whitewash a little." (Mark Twain, The Adventures of Tom Sawyer, 1920[1876])

Across the board, workshop participants saw as problematic the treating of work and play as binary opposites. Drawing from Goffman (1974), the issue may be less whether something actually is work or play (by whatever definition we choose), but rather how it is framed in a situated cultural context. The argument that "play vs. work" is a false dichotomy is not a new one. The same conversation erupted 30 years ago within the Association for the Study of Play (TASP), ${ }^{1}$ of which Brian Sutton-Smith was a founding member. In an eloquent paper in their 1978 conference proceedings, Phillips Stevens argued that the false dichotomy between play and work has resulted in a rut that "may stand in the way of any meaningful advances in several aspects of the field of our study" $(1978,329)$. Jumping off from Huizinga's canonical definition $(1950,13)$, Stevens argues that one way to resolve this dichotomy is to emphasize the experiential rather than formal aspects of each. Drawing from Csikszentmihalyi's notion of "flow" (1974), he proposes a new paradigm based on an experiential analysis. Flow, he points out, occurs across experiences, which are branded as both work and play, which also helps us rectify the apparent contradictions between ambiguous activities such as art and professional sports. All of these different types of experiences share the feature of "flow", which provides us with one example of a different lens from which to view these activities and bridge this gap.

Nonetheless, the way this dichotomy is framed within the culture often leads to an unimaginative co-opting of play space for conventional work practices. For instance, the pattern with corporate space in Second Life has been to simply replicate corporate or work culture in virtual space, rather than taking advantage of the existing play and imagination cultures afforded by the world's environment. We see endless screenshots of avatars in suits at business meetings, puppeting, in a strange way, the seriousness of business. It is as if they are playing at being at work.

A counterexample to such trends is provided by the Virtual Team Building Games (VTG) project at IBM Research, which aims to move beyond replicating real-world business practices (e.g. meetings) in virtual worlds and instead explores the unique affordances virtual worlds might bring to bear on business problems. Specifically, the VTG team has built cooperative games that provide a way for distributed teams to establish essential common ground and collaboration skills often missing from distance collaboration (Ellis et al., 2008). This work provides an early example of the ways large corporations might begin to use virtual worlds to explicitly incorporate productive play into business practices.

At the same time we see denizens of games and virtual worlds putting tremendous creative, organizational, and collaborative effort into activities framed as "play". T.L. Taylor has written about the labor of "power gamers" as well as pro gamers and modders (2003a), and Steven Poole has pointed out that games like World of Warcraft reinforce the capitalist values of repetitive and mechanized tasks that are often referred to as "grinding" (Poole, 2008). When Pearce asked selftitled Sims Online refugees in virtual world There. com why they had left the game, they said they were tired of "greening" (maintaining optimum levels of health and happiness), and that the gameplay was "too much like work". Yet in Nardi's studies of World of Warcraft players, expressions like "good work" and "hard work" were used as high praise for players collaborating on complex raids and collaborative tasks.

In Web 2.0-style virtual worlds such as There.com and Second Life, players' creative efforts indeed create the very worlds they inhabit. Numerous hours of effort are spent under the auspices of play in creating buildings, furniture, fashion, vehicles, and games, as well as designing and maintaining communities, planning events, and even running large-scale operations, such as the University of There, a virtual university run and staffed entirely by players (Pearce, 2008). The contextual framing of such activities as "play" is crucial. Players are undertaking these efforts at their own behest, or even on commission from other members, but such tasks in the context of a play frame are perceived as a facet of play practice. At the same time, players frequently report cycles of "burn-out", often fueled by a sense of obligation or responsibility, when play begins to feel like work rather than an enjoyable diversion.

\section{IDENTITY}

I was at an IBM meeting in Second Life. Present were four female avatars, a robot, and a monster. Suddenly I realized from the voices on the phone that I was the only woman present. (IBM employee)

The avatar can be viewed as the "raw material" of identity in virtual worlds. Its ubiquity begs the question "Avatar? What is it good for?". What, for instance, is the benefit of having an avatar over, say, video? Doesn't video-conferencing provide a sense of co-presence? Do we really need threedimensional cartoon characters to represent us in virtual worlds? LambdaMOO's affordances of text-based description allowed for more poetic representation: "A tall dark stranger in a well-worn but expensive hat", or "A floating orb of light" would be perfectly serviceable avatar representations in a text-based world. 
The "presence" community has long debated the value of video vs. avatar representation and extensive research has been done on this topic. A 2006 workshop at USC's Centers for Creative Technologies, organized by workshop participant Jacquelyn Ford Morie, explored a range of issues concerning presence in traditional virtual reality versus online virtual worlds (ICT Presence Workshop 2006). Some key questions that arose were: How do we measure presence, indeed can we? Isn't presence a subjective experience? What are the different dimensions of presence? Pearce's research (Pearce, 2006b) uncovered the phenomenon of "seeing and being seen", the fact that having one's avatar observed by others enhances the sense of presence and identity. The notion of role-playing was also explored: What does it mean to exist in a space of shared fantasy? What do we learn from and about each other through imagination that we might not learn otherwise? Does adopting an alternative role open up opportunities for new types of interaction, or new forms of creative expression, new modes of collaboration? Workshop organizer Ellis observed that co-workers in an avatar-based world are less inclined to observe hierarchies and thus feel more comfortable sharing ideas with higher-ups.

What role does gender play? Research has shown that in many online worlds in North America and Europe, a large proportion of female avatars are operated by male players (Yee, 2003). Yet female players rarely play male characters (Taylor, 2003a; Graner Ray, 2004; Nardi, 2008). Does cross-gender play present opportunities for rethinking gender roles and communication in the workplace? Deborah Tannen's early work on inter-gender communication showed that men and women use different speech patterns and rhetorical tactics in business settings $(1990,1994)$. Can gender re-representation mitigate or provide opportunities to interrogate these patterns? Or is cross-gender play, as Workshop participant Nick Yee suggests, merely another way to control and objectify the female body (Yee, 2003)?

It should be noted that findings on gender and game play must be understood as arising from particular cultural locales and conditions. In China, for example, males largely avoid playing female characters in World of Warcraft because of the attribution "lady-boy" (Nardi, 2008). Lady-boy (人 妖) connotes transvestism or transsexuality. One study participant said when asked why he avoided playing female characters:

I don't know. I just dislike turning into a ladyboy. Although the game is a virtual one, a boy is supposed to be a boy and a girl is supposed to be a girl.... Before this game, I played a Chinese game in which boys and girls could get married. If the two are both boys, I would feel disgusted.

Another said:
My characters are all male. If I picked a female character, they would call me a ladyboy.

Another question that arises is the issue of anonymity and multiple identities. Workshop participant T.L. Taylor has written about the "multiple bodies" enabled by avatar identity (Taylor, 2003b), an insight that parallels Goffman's (1974) observations that human behavior is defined largely by role and context: we behave differently in the roles of parent, student, CEO, friend, basketball coach. Similarly, avatar embodiment adds new personas to our repertoires.

The notion of anonymity is often misconstrued and oversimplified: while it is true that you can divorce your avatar identity from your real-world identities, avatar identities are, by definition, persistent, fixed, and cumulative over time. Once you pick your avatar name, even in worlds where you can change your virtual body at a whim, such as Second Life, your name is the permanent marker of identity. In World of Warcraft, Nardi observed that players often called other players by a single avatar name, even when the player was playing an alternative character (and hence a character with a different name). There seemed to be a desire to establish a stable identity for others, an acknowledgment that a single human being was behind the multiple characters.

A persistent identity allows for long-term character development that can often lead to profound shifts in self-perception. Pearce observed how players in a virtual world often find themselves developing creative talents they were not aware they had through an emergent process of experimentation and social feedback $(2006,2007)$. Players who had no previous artistic or design training become prolific creators, artists, designers, often attracting a large following within their communities. In some cases, these alternative roles can influence real-world identity. Pearce reported that players sometimes shifted career directions based on talents discovered and developed through their play lives. Can such hidden talents be similarly unleashed in work-related virtual world applications? Not likely if replicating corporate headquarters is the primary paradigm. But perhaps some of the benefits of play could be fully embraced to help expand creativity and collaborative potential, such as the team-building and collaboration games developed in Second Life by co-editor Ellis's group at IBM, referenced above. In their landmark report Beyond productivity, Mitchell et al. (2003) demonstrated how technology research and invention that originates in the context of fine arts has expanded the scope of IT research. By approaching technological problems from a perspective of aesthetics, experience design, or cultural critique, artists can often redefine the problem space to arrive at radically innovative outcomes. Does play have a similar potential to expand innovation, creativity, and even technical progress? Given earlier comments that play spaces are overtaxing commercial computer capabilities in a business context, could it also be argued that 
play has become the dominant driver for hardware development? Has play surpassed business and commerce as the new frontier of computation?

While it is possible to develop multiple avatars, to adopt cross-gender avatars, and to maintain some distance from one's real-world life while in a virtual world, the increasingly common use of voice technology as part of virtual world experience moves us toward something much more prosaically like real life. One's gender, for example, is immediately apparent from voice. While the men at IBM may have been having fun with female avatars, they were in no sense role-playing or gender bending. It was really just Fred in sales at the other end of the avatar. He talked like Fred, had Fred's sense of humor, and Fred's tendency to tell long stories - he was in fact Fred. In games such as World of Warcraft where real life is kept more at bay, it is nonetheless obvious from voice chat who is quiet and who is not, who tells good jokes, who is not afraid to use swear words (they are perhaps easier to type and WoW is an environment in which a wider range of language is permissible). One raid leader in Nardi's guild who played a diminutive female gnome, while invoking work-like language, always affectionately called those in his raids "fuckers" - “Good night fuckers, good job tonight."

Such discourse, extremely common in WoW and other online games, suggests that however much we may see work and play blending, there are still sharp separations in terms of acceptable customary discourse and action. Lines are drawn and maintained. The notion of a play worldin which boundaries normally defended in ordinary life can be playfully breached sustains play as a separable arena of human activity. Our enthusiasm for drawing inspiration from virtual-world activity and attempting to import it to school or work must be tempered by a virtual reality check in which we acknowledge that play spaces are separate by design. As psychologist Brian Vandenberg observed:

[In play] it is thrilling to transform the real to the not real, to journey into forbidden areas of darkness behind the public mask of conventionality, and to become aware of the freedom to do so in the process. (Vandenberg 1998, p. 201)

Work, at least in its manifestations in capitalist societies, may intrude on and dilute play, which attempts to separate itself through enclosure physical spaces such as playgrounds, tennis courts, card tables, playhouses, tree forts, casinos, football fields, and so on, and virtual spaces such as Second Life or World of Warcraft. We can safely say that the binaries examined and challenged at the workshop are extremely complex, entailing much nuance that requires further reflection and inquiry.

\section{SPACE}

Avatar embodiment and space are intimately interconnected, but we can also think of space as a social construct, a means to define the cultural expectations of a particular context. Sociologist Erving Goffman, in his work on "occasioned behavior" (1963) pointed out that behavior that might be acceptable in one context or space could be viewed as socially unacceptable in another. Thus metaphors of space also become markers of behavior; the qualities of virtual space provide us with behavioral cues, even in worlds we have never before entered. In World of Warcraft, killing other people, in the form of players and non-player characters, is perfectly acceptable, even required, provided you are in places where such behavior is sanctioned. In most social virtual worlds, killing other players is not possible, and violent play is constrained to areas set aside for that purpose. Corporate interventions into space defined for the purpose of "play", such as advertisements, virtual retail outlets, or corporate work spaces, are often viewed with disdain by participants, who see such interventions as diluting or cheapening the play experience. These intrusions abound in more openended virtual worlds, but are virtually nonexistent in game worlds that have set themes and narratives.

Thus the design of space, in terms of both its content and aesthetic, provide information about what is appropriate. And yet, in open-ended virtual worlds, these cues may sometimes be missing or ambiguous. Players create elaborate spatial constructs whose primary role is to convey a particular set of social conventions. In Caledon, a large Victorian steampunk community in Second Life, the theme, embodied in the space, establishes certain social conventions and creative parameters. Further, players joining this community must sign a covenant agreeing to role-play in a manner becoming of Victorian gentlemen and ladies, including bowing and curtseying and foregoing flying, the most common form of transit in Second Life.

When we consider the metaphoric and social functions of virtual space (DiPaola \& Collins, 2003) in light of Goffman's theories, it becomes clear where some of the tensions might emerge from trying to conjoin different types of "occasioned behavior" in a virtual world. Play environments, as it turns out, can have very strict moral codes and ground rules; social conventions that are not explicit may become so when particular emergent behaviors come to the fore. Earlier examples include the manner in which laws emerged in LambdaM00; people were not aware they had rights until they were violated (Dibbell, 1993; Mnookin, 1996). A more recent example is a guild from World of Warcraft that raided another group that was holding a funeral for one of their guild members who had died in real life (Combs, 2008). The raiding group was offended by the incursion of real life into the game space. Similarly, commercial uses of virtual space, such as simulations of conventional retail 
outlets (e.g. American Apparel in Second Life) or corporate headquarters (IBM) in Second Life seem out of touch with the world's "indigenous" culture. Understanding what is appropriate in such worlds can be challenging, especially in worlds whose societies are not structured around a game. It is easier to know what you are supposed to do in the context of an experience with a clear goal. Yet even so, game worlds can also be co-opted for uses outside their intentions. World of Warcraft has been called "the new golf" (Fairfield, 2006), and in May 2008 a group of academics gathered inside its fictional world of Azeroth to hold an academic conference. Bohannon, documenting the event (2008), also attended by the authors, noted that the change in context also led to a change in social roles, as well as behavior. Rules of order for panel presentations and $0 \& A$ were not clearly articulated and there was a casual and playful air that is absent from traditional conferences. The affordance of text chat also allowed multiple concurrent threads in the conversation, a phenomenon that would not be possible in a physical context. The fact that all the participants were presenting as Orcs, Tauren, and Blood Elves added to the layers of mediation and shifted the social expectations that might accompany the traditional social conventions of a "conference".

\section{CONCLUSION}

While these contexts and practices seem, at first blush, to clash, they also provide opportunities for levels of engagement that are lacking from traditional spaces of work and play. Furthermore, game software, and particularly virtual world software, contains many features and affordances that could potentially improve the usability, quality, and appeal of distributed work software. The aesthetic of having an articulated environment, combined with dynamic representations of others, enhances the sense of presence and engagement. The design of online games and virtual worlds is driven by the very real concern that if the environment is not fun and highly usable, the companies who produce the worlds will lose customers. Distributed work software, which is rarely discretionary, does not necessarily operate at such high standards of design. Perhaps developers of such software could take some ideas from game and virtual world designers when designing the next generation of software work environments. As articles in this special issue indicate, ongoing and future research by the organizers and a number of participants in the workshop is both working, and playing, towards this goal.

\section{NOTES}

1. Formerly the Association for the Anthropological Study of Play.

\section{REFERENCES}

Bessiere, K., Ellis, J., \& Kellogg, W. (2009). Acquiring a professional "second life:" problems and prospects for the use of virtual worlds in business. In Proceedings of ACM CHI 2009 Conference on Human Factors in Computing Systems, Boston, MA.

Bohannon, J. (2008). Slaying monsters for science. Science 320(5883), 1592. Retrieved from http://www.sciencemag. org/content/320/5883/1592.3.full

Caillois, R. (1961). Man, play and games. New York: The Free Press.

Castronova, E. (2001). Virtual worlds: A firsthand account of market and society on the cyberian frontier. CESifo Working Paper Series No. 618.

Csikszentmihalyi, M. (1974). Studies of enjoyment. Chicago: PHS Research

Combs, N. (2008). The price of serenity? TerraNova Blog, April 15, 2006. Retrieved [date] from http://terranova.blogs.com/ terra_nova/2006/04/serene.html

Curtis, P. (1992). Mudding: Social phenomena in text-based virtual realities. In Proceedings of the 1992 Conference on Directions and Implications of Advanced Computing, Berkeley, California. ftp://ftp.lambda.moo.mud.org/pub/ M00/papers/DIAC92.txt

Dewey, J. (2005). Art as experience. New York: Perigee (first published 1934).

Dibbell, J. (1993). A rape in cyberspace: How an evil clown, a Haitian trickster spirit, two wizards, and a cast of dozens turned a database into a society. The Village Voice, December 21, 36-42.

Dibbell, J. (2007). The life of the Chinese gold farmer. The New York Times Magazine. June.

Dipaola, S., \& Collins, D. (2003). Social metaphor-based 3d virtual environment. In Proceedings, SIGGRAPH 2003, San Diego, California. ACM SIGGRAPH.

Ellis, J., Luther, K., Bessiere, K., \& Kellogg, W. (2008). Games for virtual team building. In Proceedings of ACM DIS 2008 Conference on Designing Interactive Systems. Cape Town, South Africa.

Fairfield, J. (2006). World of Warcraft is the new golf. TerraNova Blog. August 7, 2006. Retrieved [date] from http://terranova. blogs.com/terra_nova/2006/02/world_of_warcra.html

Farmer, R., \& Morningstar, C. (1991). Lessons of Lucasfilm's Habitat. In M. Benedikt (Ed.), Cyberspace: First steps (pp. 273-302). Cambridge, MA: MIT Press.

Goffman, E. (1963). Behavior in public places: Notes on the social organization of gatherings. New York: Macmillan/ Free Press.

Goffman, E. (1974). Frame analysis: An essay on the organization of experience. London: Harper \& Row.

Graner Ray, S. (2004). Gender inclusive game design: Expanding the market. Hingham, MA: Charles River Media.

Huizinga, J. (1950). Homo ludens: A study of the play-element in culture. New York: Roy Publishers. 
IBM (2007). Virtual worlds, real leaders: Online games put the future of business leadership on display. Retrieved June 2008 from http://www.seriosity.com/downloads/GIO_PDF_web. pdf

ICT Presence Workshop. (2006). Retrieved from http://people. ict.usc.edu/ morie/PresenceWorkshop2006.html

Klastrup, L. (2003). A poetics of virtual worlds. In A. Miles (Ed.), Proceedings digital arts and culture, Melbourne, Australia, pp. 100-109.

MacMillan, D. (2007). Special report: Virtual life virtual worlds rich list. Business Week Online, April 16, 2007. Retrieved June 2008 from http://www.businessweek.com/technology/ special_reports/20070416virtuallife.htm

Michell, W., Injouye, A., \& Blumenthal, M. (2003). Beyond productivity: Information, technology, innovation, and creativity. Washington, DC: National Academies Press.

Mnookin, J. (1996). Virtual(ly) law: The emergence of law in LambdaM00. Journal of Computer-Mediated Communication, 2(1). Retrieved June 2008 from http://dx.doi. org/10.1111/j.1083-6101.1996.tb00185.x

Nardi, B. (2005). Beyond bandwidth: Dimensions of connection in interpersonal interaction. The Journal of ComputerSupported Cooperative work, 14, 91-130.

Nardi, B. (2009). My life as a night elf priest: An anthropological account of World of Warcraft. Under review.

Pearce, C. (and Artemesia) (2006a). Productive play: Game culture from the bottom up. Games \& Culture 1(1), 17-24.

Pearce, C. (2006b). Seeing and being seen: Presence \& play in online games and virtual worlds. Position Paper for Online, Offline \& the Concept of Presence - When Games and VR Collide. October 25-27, Institute for Creative Technologies, University of Southern California.

Pearce, C. (2008). The truth about baby boomer gamers. A study of over-forty computer game players. Games and Culture, 3, 142-174.

Pearce, C. (2009). Communities of play: Emergent cultures in multiplayer games and virtual worlds. Cambridge, MA: MIT Press (in press.)

Poole, S. (2008). Working for the man: Against the employment paradigm in videogames. Keynote Presentation, Future and Reality of Games. Retrieved June 2008 from http:// stevenpoole.net/trigger-happy/working-for-theman/

Reeves, B., \& Malone, T. (2007). Leadership in games and at work: Implications for the enterprise of massively multiplayer online roleplaying games. Retrieved June 2008 from http:// www.seriosity.com/downloads/Leadership_In_Games_ Seriosity_and_IBM.pdf

Rohall, S., Cheng, L., \& Patterson, J. (2008). Bluegrass: Lessons for deploying virtual worlds within the enterprise. Position Paper, Computer-Supported Cooperative Work Conference 2008 - Virtual Worlds, Collaboration, and Workplace Productivity Workshop, San Diego.

Stevens, P., Jr. (1978). Play and Work: A False Dichotomy. Play \& Culture: 1978. Proceedings of the Association for the Anthropological Study of Play. West Point: Leisure Press.

Sutton-Smith, B. (1997). The ambiguity of play. Cambridge, MA: Harvard University Press.
Syamsuddin, M., and Mayangsari, M. (2008). Trying to Integrate ubiquitous robotic space and metaverse. Position Paper, Computer-Supported Cooperative Work Conference 2008 - Virtual Worlds, Collaboration, and Workplace Productivity Workshop, San Diego.

Tannen, D. (1990). You just don't understand: Women and men in conversation. New York: William Morrow.

Tannen, D. (1994). Talking from 9 to 5: Women and men at work. New York: William Morrow.

Taylor, T.L. (2003a). Power gamers just want to have fun?: Instrumental play in a MMOG. In M. Copier, \& J. Raessens (Eds.), Proceedings Level Up: Digital Games Research Association (DiGRA). Utrecht, The Netherlands: Universiteit Utrecht.

Taylor, T.L. (2003b). Multiple pleasures: Women and online gaming. Convergence, 9, 21-48.

Tolkien, J.R.R. (1983). The monsters and the critics and other essays. Reprinted with additional material, New York: HarperCollins, 1997.

Twain, M. (1920[1876]). The adventures of Tom Sawyer. New York: Harper \& Brothers.

Vandenberg, B. (1998). Real and not real: A vital developmental dichotomy. In 0. Saracho, \& B. Spoedek (Eds.), Multiple perspectives on play in early childhood education. Albany, NY: SUNY Press.

Yankelovich, N., \& Kaplan J. (2008). Improving virtual world presentations. Position Paper, Computer-Supported Cooperative Work Conference 2008 - Virtual Worlds, Collaboration, and Workplace Productivity Workshop, San Diego.

Yee, N. (2003). The demographics of gender bending. The Daedalus Project. Retrieved June 2008 from http://www. nickyee.com/daedalus/archives/000551.php

Yee, N. (2006). The labor of fun: How video games blur the boundaries of work and play. Games \& Culture, 1(1), 6871.

\section{CORRESPONDENCE}

Bonnie Nardi, Department of Informatics, University of California, Irvine, CA 92697-3440, USA.

E-mail:nardi@uci.edu

Published online 19 0ctober, 2011

ISSN 1749-3463 print/ ISSN 1749-3471

DOI: $10.1080 / 17493460902898786$

(C) 2008 Artifact 